\title{
HACIA UN NUEVO ENFOQUE DE LA TEORÍA DE LA RESPONSABILIDAD ADMINISTRATIVA PARA LA GOBERNABILIDAD
}

\author{
TOWARDS A NEW APPROACH TO \\ THE THEORY OF ADMINISTRATIVE \\ RESPONSIBILITY FOR GOVERNANCE
}

Pedro Patrón Bedoya*

* Abogado por la Universidad Nacional Mayor de San Marcos, post grado en administración pública por la Escuela Nacional de Administración Pública de Caracas - Venezuela, coautor de libros de derecho administrativo sobre legislación y doctrina desde 1974, Consultor Internacional En EI BID, Banco Mundial, AID. Investigador Y Colaborador en diversos artículos sobre derecho administrativo y derecho de las tecnologías, expositor nacional e internacional en temas de sus especialidades. Ha sido docente en diversas universidades privadas y públicas. Actualmente es integrante de la Junta Directiva del llustre Colegio de Abogados de Lima como Vicedecano de la Orden.

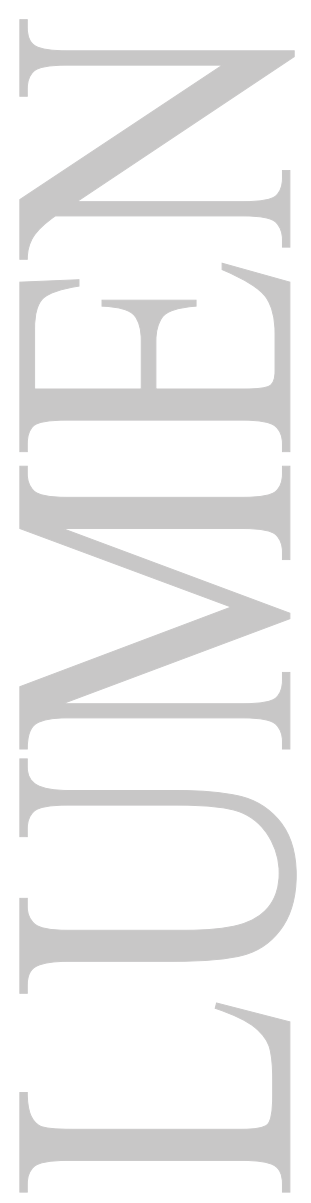




\title{
HACIA UN NUEVO ENFOQUE DE LA TEORÍA DE LA RESPONSABILIDAD ADMINISTRATIVA PARA LA GOBERNABILIDAD
}

\author{
TOWARDS A NEW APPROACH TO THE THEORY OF ADMINISTRATIVE \\ RESPONSIBILITY FOR GOVERNANCE
}

Pedro Patrón Bedoya

\begin{abstract}
Resumen:
El presente artículo desarrolla una perspectiva innovativa relacionada a la responsabilidad administrativa para la gobernabilidad y citando a Haldenwang C., nos señala el concepto de Gobernanza: "El concepto de Gobernanza es una idea básica compartida por la mayor parte de las organizaciones internacionales. Este enfoque abarca la presencia de instituciones políticas democráticas y legítimas, una administración pública, eficiente y responsable, la vigencia del Estado de derecho, el respeto de los derechos fundamentales y una eficaz regulación pública de los mercados".

El autor señala que este término ha superado a los conceptos de Gobierno y Gobernabilidad y no obstante su estudio, para nuestra realidad, está en relación a la Gobernabilidad y el nuevo enfoque aplicable a la teoría de la responsabilidad.
\end{abstract}

\section{Palabras clave:}

Gobernabilidad, gobernanza, responsabilidad administrativa, enfoque aplicable.

\begin{abstract}
:
This article develops an innovative perspective related to the administrative responsibility for governance and citing Haldenwang C., the concept of Governance points out: "The concept of Governance is a basic idea shared by most international organizations. This approach covers the presence of democratic and legitimate political institutions, a public administration, efficient and responsible, the rule of law, respect for fundamental rights and effective public regulation of markets ".

The author points out that this term has surpassed the concepts of Government and Governance and despite its study, for our reality, it is in relation to Governance and the new approach applicable to the theory of responsibility.
\end{abstract}

\section{Key words:}

Governance, governance, administrative responsibility, approach.

\section{INTRODUCCIÓN}

La Gobernabilidad nos lleva a analizar su relación con los términos Gobernanza y Gobierno. Al respecto tenemos que la gobernabilidad deber ser entendida ${ }^{1}$ :

"Como —un estado de equilibrio dinámico entre el nivel de las demandas sociales y la capacidad del sistema político (estado/gobierno) para responderlas de manera legítima y eficaz" ॥

Antonio Camou - 2001:36 
Por otro lado tenemos que Gobierno se conceptualiza²:

"El gobierno se refiere a los gobernantes, el grupo de personas que se hallan al frente del Estado en un momento determinado."

El Dr. Grenfieth de Jesús Sierra Cadena ${ }^{3}$, citando a Haldenwang C., nos señala el concepto de Gobernanza:

"El concepto de Gobernanza es una idea básica compartida por la mayor parte de las organizaciones internacionales. Este enfoque abarca la presencia de instituciones políticas democráticas y legítimas, una administración pública, eficiente y responsable, la vigencia del Estado de derecho, el respeto de los derechos fundamentales y una eficaz regulación pública de los mercados"

Este último término ha superado a los conceptos de Gobierno y Gobernabilidad, no obstante, nuestro enfoque de estudio, para nuestra realidad, está en relación a la Gobernabilidad y el nuevo enfoque aplicable a la teoría de la responsabilidad.

Siendo así, con relación al enfoque de Gobernabilidad, es preciso partir esencialmente del enfoque de la responsabilidad que hace la Constitución Política del Perú. El artículo $45^{\circ}$ nos hace la presente descripción:

Artículo $45^{\circ}$

Origen y Ejercicio Estatal

El poder del Estado emana del pueblo. Quienes lo ejercen lo hacen con las limitaciones y responsabilidades que la Constitución y las leyes lo establecen. (El subrayado es nuestro)

Ninguna persona, organización, Fuerza Armada, Policía Nacional o sector de la población puede arrogarse el ejercicio de ese poder. Hacerlo constituye rebelión o sedición.

Desde el punto de vista de su interpretación tenemos lo siguiente ${ }^{4}$ :

“(...) nos acogemos a la Teoría Liberal entiendo que el Poder del Estado Emana del Pueblo, quienes eligen a los gobernantes que ejercen el poder sometidos a limitaciones y responsabilidades que la Constitución y las leyes establecen, ideas, entendiéndose esto como el Estado de Derecho, es decir, el poder no se ejerce al arbitrio del gobernante, sino que estos están subordinados a la supremacía de la Ley.

Desde esta jerarquía podemos observar que, la Constitución Política del Perú no delinea el concepto de responsabilidad, más aún desde el punto de su interpretación no se ha hecho un análisis a fondo, por lo que desde su descripción literal, se ha dejado de lado los conceptos de obligaciones y deberes de los funcionarios que forman parte del aparato estatal lo que supone que exista un carácter negativo en la actual teoría de la responsabilidad administrativa, que se aplica actualmente en nuestro país.

Frank Bealey (2003) Diccionario de Ciencia Política. Editorial ISTMO. Madrid - España.

3 LA JUSTICIA CONSTITUCIONAL EN LA ERA DE LA GOBERNANZA (Un análisis de perspectiva comparada desde la periferia del derecho) - Artículo publicado en Universitas - Revista de Filosofía, Derecho y Política, $n^{\circ} 13$, enero 2011, ISSN 1698-7950, pp. 67-95.

4 Raúl Chanamé Orb y otro. En:La Constitución Comentada (2013)Director Walter Gutiérrez Camacho. Editorial Gaceta Jurídica. Pp. 953 y Ss. 
El termino responsabilidad ha sido pues desnaturalizado

Siendo así podemos observar que en el Perú legalmente la responsabilidad tiene el siguiente enfoque:

\section{Desde el punto de vista de las funciones y responsabilidades:}

Debemos considerar que el estado en tanto estructura organizada de poder, tiene como función garantizar una convivencia ordenada y sin contradicciones y, en especial, la paz y la seguridad jurídica. Asimismo las responsabilidades en la administración pública radican en las consecuencias derivadas de las acciones u omisiones las cuales deben producirse dentro de las funciones asignadas al empleado del estado peruano. ${ }^{5}$ La presente descripción en concreto, se aplica para los gobiernos nacionales, regionales y locales los cuales se encuentran sujetos a fiscalización de manera interna y externa los cuales consisten: "En términos de la Ley Orgánica del Sistema Nacional de Control y de la Contraloría General de la República (Ley $N^{\circ} 27785$ ), el control gubernamental es interno y externo y su desarrollo constituye un proceso integral y permanente. El control interno compete a las autoridades, funcionarios y servidores públicos de las entidades y el control interno posterior es responsabilidad del superior del servidor o funcionario ejecutor. Por su parte el control externo se conceptualiza como el conjunto de políticas, normas, métodos y procedimientos técnicos que aplica la Contraloría General de la República u otro órgano del sistema."”

Siendo así tenemos que desde el punto de vista de la Autonomía de la Responsabilidad y el $\mathrm{Ne}$ bis In Idem, tipificado en la Ley del Procedimiento Administrativo General, respectivamente, podemos observar que la autonomía de la responsabilidad de materia administrativa y penal se presenta siempre y cuando los fundamentos o bienes jurídicos sean diferentes, a fin de que no se contravenga con el principio o regla del non bis in ídem.

\section{Desde el punto de vista de la Ética y de la Función Pública}

Desde la perspectiva del Código de Ética regulado por la Ley $N^{\circ} 27815$, tenemos que en el numeral 6 del artículo $7^{\circ}$ y artículo $10^{\circ}$ respecto a las responsabilidades administrativas nos señala lo siguiente:

\section{Artículo 7.- Deberes de la Función Pública}

El servidor público tiene los siguientes deberes:

\section{Responsabilidad}

Todo servidor público debe desarrollar sus funciones a cabalidad y en forma integral, asumiendo con pleno respeto su función pública.

\section{Artículo 10.- Sanciones}

10.1 La transgresión de los principios y deberes establecidos en el Capítulo II y de las prohibiciones señaladas en el Capítulo III, de la presente Ley, se considera infracción al presente Código, generándose responsabilidad pasible de sanción.

5 M.C.s. Víctor Andrés Villar Narro (2014) La función pública y la responsabilidad administrativa en el ordenamiento jurídico peruano. Ministerio de Justicia.

6 Daniel Marquez (2005) Función jurídica de control de la administración pública. Instituto de Investigaciones JurídicasUniversidad Nacional Autónoma de México. 
Siendo así, y a manera de aplicación lo dispuesto por el Código de Ética, tenemos la Ley $\mathrm{N}^{\circ}$ 27806, Ley de Transparencia y Acceso a la Información y Gestión, donde en su artículo $4^{\circ}$ nos describe lo siguiente:

Artículo $4^{\circ}$.- Responsabilidades y Sanciones

Todas las entidades de la Administración Pública quedan obligadas a cumplir lo estipulado en la presente norma.

Los funcionarios o servidores públicos que incumplieran con las disposiciones a que se refiere esta Ley serán sancionados por la comisión de una falta grave, pudiendo ser incluso denunciados penalmente por la comisión de delito de Abuso de Autoridad a que hace referencia el Artículo $377^{\circ}$ del Código Penal.

El cumplimiento de esta disposición no podrá dar lugar a represalias contra los funcionarios responsables de entregar la información solicitada.

No, obstante lo señalado tenemos las Resoluciones Legislativas $\mathrm{N}^{\circ} 26757$ y $\mathrm{N}^{\circ} 28357$, que aprueban Convención Interamericana contra la Corrupción y la Convención de las Naciones Unidas contra la Corrupción, respectivamente, las mismas que se aplican en el Estado Peruano regulan.

Convención Interamericana contra la Corrupción

Artículo III

Medidas Preventivas

Los Estados Partes convienen en considerar la aplicabilidad de medidas, dentro de sus propios sistemas institucionales, destinadas a crear, mantener y fortalecer:

3. Instrucciones al personal de las entidades públicas, que aseguren la adecuada comprensión de sus responsabilidades y las normas éticas que rigen sus actividades.

Convención de las Naciones Unidas contra la Corrupción

Artículo 26

Responsabilidad de las personas jurídicas

2. Con sujeción a los principios jurídicos del Estado Parte, la responsabilidad de las personas jurídicas podrá ser de índole penal, civil o administrativa.

\section{Desde el Punto de Vista del Ámbito Funcional}

Al respecto tenemos que el Decreto Ley $N^{\circ} 11377$, Estatuto y Escalafón del Servicio Civil, que crea la Carrera Administrativa, estableciendo la forma de ingreso a ella, las pautas a que deben sujetarse los ascensos y promociones, $y$, a su vez las sanciones a que se hagan acreedores los que infrinjan las disposiciones reglamentarias donde en su artículo $81^{\circ}$ consigna las sanciones a que se harán acreedores los empleados públicos, por faltas de carácter disciplinario, asimismo la Ley $\mathrm{N}^{\circ} 27588$, Ley que Establece Prohibiciones e Incompatibilidades de Funcionarios y Servidores Públicos, así como de las personas que presten servicios al Estado bajo cualquier Modalidad Contractual, tenemos en su artículo $1^{\circ}$ lo siguiente: 


\section{Artículo 1.- Objeto de la ley}

Los directores, titulares, altos funcionarios, miembros de Consejos Consultivos, Tribunales Administrativos, Comisiones y otros órganos colegiados que cumplen una función pública o encargo del Estado, los directores de empresas del Estado o representantes de éste en directorios, así como los asesores, funcionarios o servidores con encargos específicos que, por el carácter o naturaleza de su función o de los servicios que brindan, han accedido a información privilegiada o relevante, o cuya opinión haya sido determinante en la toma de decisiones, están obligados a guardar secreto o reserva respecto de los asuntos o información que por ley expresa tengan dicho carácter.

Tampoco podrán divulgar ni utilizar información que, sin tener reserva legal expresa, pudiera resultar privilegiada por su contenido relevante, empleándola en su beneficio o de terceros y en perjuicio o desmedro del Estado o de terceros.

La violación de lo dispuesto en el presente artículo implicará la transgresión del principio de buena fe y será sancionada con la inhabilitación para prestar servicios al Estado, sin perjuicio de las acciones administrativas, civiles y penales a que hubiera lugar.

La presente disposición se complementa con lo dispuesto por la Ley $\mathrm{N}^{\circ} 27658$, Ley de Modernización de la Gestión del Estado la cual refiere en su artículo $4^{\circ}$ lo siguiente:

Artículo 4.- Finalidad del proceso de modernización de la gestión del Estado

El proceso de modernización de la gestión del Estado tiene como finalidad fundamental la obtención de mayores niveles de eficiencia del aparato estatal, de manera que se logre una mejor atención a la ciudadanía, priorizando y optimizando el uso de los recursos públicos. El objetivo es alcanzar un Estado:

a) Al servicio de la ciudadanía.

b) Con canales efectivos de participación ciudadana.

c) Descentralizado y desconcentrado.

d) Transparente en su gestión.

e) Con servidores públicos calificados y adecuadamente remunerados.

f) Fiscalmente equilibrado.

Asimismo, dentro de la figura del Control Preventivo y desde el punto de Vista del Control Interno, tenemos lo establecido por la Resolución de la Contraloría N³20-2006-CG:

Roles y Responsabilidades

El control interno es efectuado por diversos niveles jerárquicos. Los funcionarios, auditores internos y personal de menor nivel contribuyen para que el sistema de control interno funcione con eficacia, eficiencia y economía.

El titular, funcionarios y todo el personal de la entidad son responsables de la aplicación y supervisión del control interno, así como en mantener una estructura sólida de control interno 
que promueva el logro de sus objetivos, así como la eficiencia, eficacia y economía de las operaciones.

Para contribuir al fortalecimiento del control interno en las entidades, el titular o funcionario que se designe, debe asumir el compromiso de implementar los criterios que se describen a continuación:

- Apoyo institucional a los controles internos:

- Responsabilidad sobre la gestión

- Clima de confianza en el trabajo

- Transparencia en la gestión gubernamental

- Seguridad razonable sobre el logro de los objetivos del control interno.

\section{Desde el Punto de Vista de la Teoría del Daño}

Debemos considerar al Daño como "el detrimento" o menoscabo a un interés jurídicamente tutelado por el ordenamiento jurídico. Al ser el daño un menoscabo a un interés jurídicamente tutelado la indemnización debe perseguir "no una sanción" sino una "satisfacción" de dicho interés conculcado.

Dentro de la figura de los Daños Patrimoniales tenemos que el Daño Emergente está referido a la pérdida efectivamente sufrida, o como señala Espinoza Espinoza "es la pérdida que sobreviene en el patrimonio del sujeto afectado por el incumplimiento de un contrato o por haber sido perjudicado por un acto ilícito, o como sostiene un sector autorizado de la doctrina italiana la disminución de la esfera patrimonial del dañado" y el Lucro Cesante ésta referido a la ganancia dejada de percibir como consecuencia del daño, se manifiesta por el no incremento en el patrimonio del dañado.

Dentro de la figura de los Daño Extra patrimoniales tenemos la teoría de la responsabilidad administrativa y el daño de conformidad con el numeral 3 del artículo 238 de la Ley $N^{\circ} 27444$, Ley de Procedimiento Administrativo General, nos describe lo siguiente:

\section{CAPÍTULO I}

Responsabilidad de la administración pública

Artículo 238.- Disposiciones Generales

$(\ldots)$

238.4 El daño alegado debe ser efectivo, valuable económicamente e individualizado con relación a un administrado o grupo de ellos.

Al respecto Morón Urbina ${ }^{7}$ nos describe, dentro de la Factibilidad Jurídica de asignar el daño a la Administración, lo siguiente:

Los factores de atribución normalmente usados son el funcionamiento anormal, defectuoso, tardío, o incorrecto de la Actividad de la Administración, en relación con sus estándares admisibles técnica o legalmente (comúnmente denominada la falta de servicio) y el riesgo creado por la acción estatal (responsabilidad por riesgo o por enriquecimiento sin causa).

Morón Urbina, Juan Carlos (2009) Comentarios a la Ley de Procedimiento Administrativo General. Editorial Gaceta Jurídica. Pp. 757. 


\section{Desde el Punto de Vista del Personal}

De conformidad con lo regulado por el Decreto Legislativo $\mathrm{N}^{\circ} 276$, ley de bases de la carrera administrativa y de remuneraciones del sector público tenemos que en sus artículos $25^{\circ}$ y $26^{\circ}$ nos describe lo siguiente:

\section{RESPONSABILIDAD CIVIL, PENAL Y ADMINISTRATIVA:}

\section{Artículo $25^{\circ}$.-}

Los servidores Públicos son responsables civil, penal y administrativamente por el cumplimiento de las normas legales y administrativas en el ejercicio del servicio público sin perjuicio de las sanciones de carácter disciplinario por las faltas que cometan.

\section{SANCIONES POR FALTAS DISCIPLINARIAS}

Artículo $26^{\circ}$.- Las sanciones por falta disciplinarias pueden ser:
a) Amonestación verbal o escrita;
b) Suspensión sin goce de remuneraciones hasta por treinta días;
c) Cese temporal sin goce de remuneraciones hasta por doce meses; $y$
d) Destitución.

La Ley 27444 nos describe la figura del procedimiento sancionador donde el mismo se desarrolla para sancionar a los administrados que presuntamente han cometido una infracción.

\section{Descripción personal a manera de Propuesta}

Es importante recordar la descripción del concepto de responsabilidad directa e indirecta:

Desde el punto de vista de la responsabilidad extracontractual tenemos la siguiente descripción que nos hace el Dr. Parada:

La responsabilidad extracontractual - también llamada aquiliana, porque fue en Roma, la Ley Aquilia la primera que la sancionó - tiene en el Derecho civil su origen y regulación matricial. Puede ser directa, o por hecho propio (el que por acción u omisión causa daño a otro interviniendo cualquier género de culpa o negligencia, está obligado a reparar el daño causado), o indirecta, por el hecho de personas o cosas sobre las que se tiene un deber de custodia o que se ha elegido para que actúen en Derecho Propio en cuyo caso se presume la culpa elemento fundamental en la regulación privatista del instituto resarcitorio. También el Derecho Administrativo conoce la responsabilidad extracontractual, institución que permite exigir de la Administración la indemnización por los daños y perjuicios que ocasiona la actividad de los poderes públicos en el patrimonio de los ciudadanos $(\ldots)^{8}$.

Siendo así podemos observar, de las normas y todo lo citado, que el enfoque sobre la responsabilidad administrativa en el Perú es de carácter negativista lo que todo lo descrito conlleva en lógica simple la figura de la causa y consecuencia, trayendo como producto que se produzca un enfoque sesgado a consecuencia de que la figura de la responsabilidad y el ilícito ha sido deformado.

8 Jorge Ramón Parada Vásquez (2010) Derecho Administrativo I, Parte General. Editorial Marcial Pons. Madrid España. Pp. 58' 
La presente propuesta es que el enfoque de la teoría de la responsabilidad administrativa sea de enfoque positivo el mismo que deberá encontrarse sujeto a las buenas prácticas por parte de la autoridad administrativa puesto que estas te van a prevenir la comisión de faltas y delitos puesto que el interés es en prevenir en la línea del enfoque moderno de la Contraloría recogido en su reciente Ley de Fortalecimiento 30742.

Este punto además es importante a consecuencia de que el concepto de responsabilidad al igual que hallazgo han sido usurpados, más aun, a manera de ejemplo, si las disposiciones de la Contraloría General de República en sus disposiciones hablaban de hallazgos y de ese modo la responsabilidad administrativa sigue siendo negativista.

\section{REFERENCIAS BIBLIOGRÁFICAS}

- Raúl Chanamé Orb y otro. La Constitución Comentada (2013) Director Walter Gutiérrez Camacho. Editorial Gaceta Jurídica. Pp. 953 y Ss.

- Morón Urbina, Juan Carlos (2009) Comentarios a la Ley de Procedimiento Administrativo General. Editorial Gaceta Jurídica

- Jorge Ramón Parada Vásquez (2010) Derecho Administrativo I, Parte General. Editorial Marcial Pons. Madrid.

- M.C.s. VíctorAndrés Villar Narro (2014) La función pública y la responsabilidad administrativa en el ordenamiento jurídico peruano. Ministerio de Justicia

- -Daniel Márquez (2005) Función jurídica de control de la administración pública. Instituto de Investigaciones Jurídicas- Universidad Nacional Autónoma de México.

- $\quad$-Frank Bealey (2003) Diccionario de Ciencia Política. Editorial ISTMO. Madrid - España. LA JUSTICIA CONSTITUCIONAL EN LA ERA DE LA GOBERNANZA (Un análisis de perspectiva comparada desde la periferia del derecho) - Artículo publicado en Universitas - Revista de Filosofía, Derecho y Política, nº 13, enero 2011, ISSN 1698-7950, pp. 67-95. 